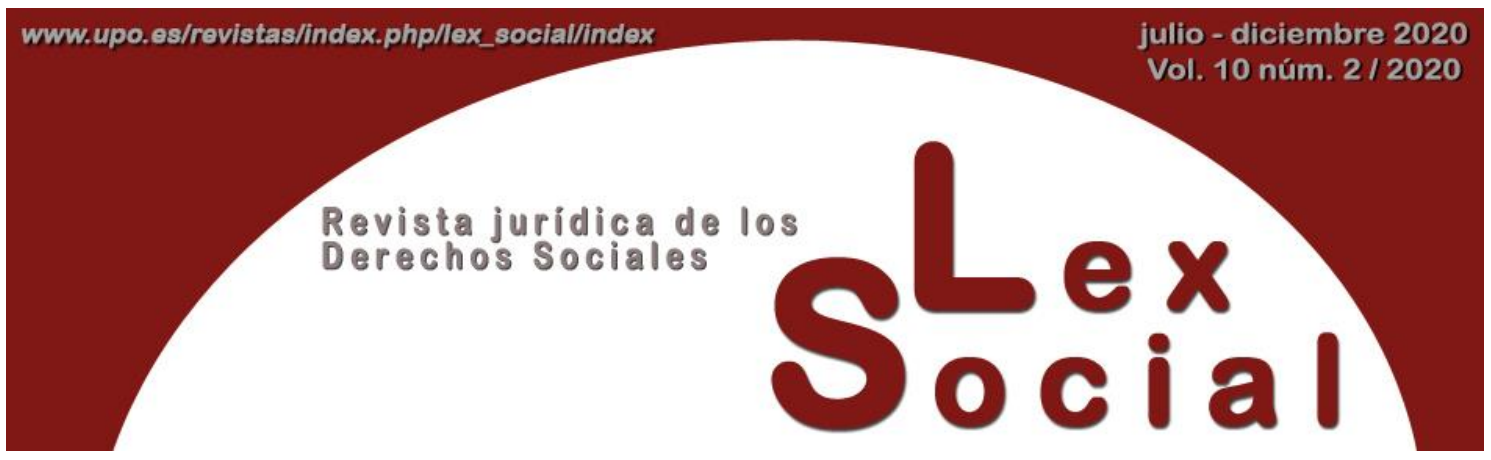

\title{
RECENSIÓN
}

\section{García González Guillermo, Régimen jurídico de los técnicos de prevención de riesgos laborales, Madrid, Dykinson, 2019}

\author{
SONIA I. PEDROSA ALQUÉZAR \\ Profesora Titular de Derecho del Trabajo \\ Universidad de Zaragoza
}

DOI: https://doi.org/10.46661/lexsocial.5091

La obra constituye un riguroso estudio sobre una de las figuras más olvidadas de la prevención de riesgos laborales: los técnicos de prevención. El autor, Guillermo García González, es un conocedor teórico y práctico de la realidad de este colectivo de trabajadores especialmente cualificados desde la óptica preventiva; conocimiento que se refleja a lo largo de todo el estudio.

Los técnicos de prevención han constituido uno de los motores principales para que el modelo preventivo diseñado por la Ley 31/1995, de Prevención de Riesgos Laborales, haya podido implantarse en nuestro sistema de relaciones laborales. Sin embargo, el rol fundamental que los técnicos de prevención de riesgos laborales han jugado en el desarrollo preventivo en nuestro país no se ha visto reflejado en una especial dedicación doctrinal a este colectivo de profesionales. Los distintos análisis que se han formulado sobre los técnicos de prevención se han centrado esencialmente en aspectos concretos ligados a su régimen de responsabilidades o a sus especiales garantías, pero existía una carencia de estudios que abordaran desde una perspectiva integral el marco jurídico de los técnicos especializados en la gestión del riesgo laboral.

No deja de sorprender este relativo desinterés doctrinal por una figura como los técnicos de prevención, teniendo en cuenta la multiplicidad de estudios que en los últimos veinticinco años se han venido desarrollando en el ámbito de la salud laboral. En este sentido, la promulgación de la Ley de Prevención de Riesgos Laborales supuso un antes y un después en la dedicación de la doctrina iuslaboralista a la seguridad y salud laboral, 
una materia que no había despertado excesivo interés desde la dimensión del Derecho del Trabajo. La Ley 31/1995- y su prolijo desarrollo reglamentario- supuso un cambio radical en este escenario, pasando la prevención de riesgos a ser una de las materias objeto de mayor interés doctrinal. Sin embargo, entre toda esta ingente producción científica en el ámbito preventivo, no se encuentra ninguna obra que aborde el marco jurídico de los técnicos de prevención de modo sistemático e integral. A integrar ese vacío se dirige la obra objeto de esta recensión.

La monografía se estructura partiendo de tres elementos: las obligaciones, las garantías y las responsabilidades de los técnicos de prevención de riesgos laborales. Son estas tres dimensiones sobre las que se articula todo el estudio. A pesar de que cada una de ellas tiene su aproximación singular, a lo largo de toda la obra aparecen contantemente interrelacionadas, pues no dejan de ser elementos que dibujan una única realidad jurídica.

Dos aspectos relevantes merecen ser mencionados como consideraciones previas. En primer lugar, el constante diálogo que el autor mantiene en su análisis entre la doctrina y la jurisprudencia, entre el derecho formal y el material y entre la teoría y la práctica. En segundo lugar, la lógica en la sistemática que sigue la obra y la claridad expositiva, que permite una aproximación rigurosa a la realidad jurídica de los técnicos de prevención.

Sin perder de vista la íntima conexión de las dimensiones jurídicas que condensan el objeto de la monografía, obligaciones, garantías y responsabilidades, el autor articula su estudio en cinco capítulos. Como se ha señalado, esta presentación sistemática facilita la lectura y estructura el análisis, lo que no obsta para que se produzcan numerosas interrelaciones e interconexiones entre elementos jurídicos que, conjuntamente, conforman el marco jurídico de los técnicos de prevención.

Los dos primeros capítulos se dedican a examinar el régimen obligacional de los técnicos de prevención de riesgos laborales. La construcción de este marco obligacional de los técnicos ha de ser valorada como una de las grandes aportaciones de la monografía, teniendo en cuenta la inconcreción que nuestro ordenamiento jurídico refiere en esta materia. Con el fin de suplir esta indefinición normativa, el autor examina detenidamente todas y cada una de las obligaciones que corresponden a los técnicos partiendo de sus competencias reglamentarias. Más allá de las competencias genéricas que se derivan del Real Decreto 39/1997, el estudio profundiza en las numerosas facultades y competencias específicas que les corresponden a los técnicos con base en el profuso desarrollo reglamentario que la Ley 31/1995 ha traído consigo. Partiendo de este esquema, el estudio profundiza en la concreta dinámica de estas obligaciones teniendo en cuenta dos elementos. Por una parte, el modelo de organización preventiva en el cual el técnico de prevención se integra y que constituye el escenario en el cual ha de cumplir sus obligaciones. Por la otra, la autonomía colectiva e individual como instrumentos de configuración del alcance y contenido efectivo de las obligaciones del técnico.

Dibujado así el marco obligacional, cada una de las obligaciones preventivas que se presentan se analiza con profundidad partiendo de su concepción doctrinal y contrastándola con su interpretación jurisprudencial. También se introducen en el análisis 
numerosas resoluciones interpretativas de distintos organismos con competencias en materia de seguridad y salud, que terminan por perfilar el marco jurídico de los profesionales de la prevención.

El tercer capítulo de adentra en las especiales garantías que tienen los técnicos de prevención. Constituye esta materia una de las que mayor interés ha despertado en la doctrina y, en consecuencia, una de las que más conflictos interpretativos ha generado. La disparidad doctrinal y su plasmación en la contradictoria jurisprudencia se constata a lo largo de todo el capítulo, que sintetiza perfectamente los principales problemas existentes en este punto. Por un lado, se examinan las principales controversias existentes en cuanto al alcance subjetivo de las garantías. Por el otro, se delimita el alcance y contenido material de las garantías que el ordenamiento asigna a los técnicos de prevención. La exigua y confusa normativa reguladora en este punto se suple, como se ha apuntado, con un completo y detallado análisis jurisprudencial y doctrinal que permite al lector llegar a conclusiones jurídicas diversas, pero todas ellas fundamentadas.

Tras las obligaciones y las garantías, los dos últimos capítulos se centran en conocer el alcance de las responsabilidades de los técnicos de prevención. Se insertan en este punto lógicas jurídicas públicas y privadas, teniendo en cuenta el complejo sistema de responsabilidades de los técnicos de prevención. Esta complejidad requiere del iuslaboralista adentrarse en materias que no le acostumbran a ser propias, como el Derecho Civil o el Derecho Penal, pero que se presentan como instrumentos indispensables para una adecuada delimitación del objeto de análisis.

Los dos capítulos dedicados a las responsabilidades de los técnicos de prevención son especialmente detallados y rigurosos en su análisis jurisprudencial. Conocer la aplicación judicial del marco jurídico en este punto es, si cabe, más esencial, teniendo en cuenta la disparidad de criterios aplicativos que acostumbran a concurrir en esta materia. El autor realiza un profuso examen jurisprudencial- especialmente en materia penal y civil- que, lejos de ser descriptivo, permite apreciar tendencias y criterios de actuación que facilitan la comprensión del auténtico alcance de las responsabilidades de los técnicos de prevención; y, todo ello, con un sustento doctrinal solvente y sólido que le permite aunar en su examen el derecho como una realidad vivida, que va más allá de la norma escrita.

Es, en definitiva, una obra que permite una aproximación rigurosa y sistemática al marco jurídico de los técnicos de prevención, profunda en su análisis y comprometida en sus propuestas. Cubre, de este modo, uno de los vacíos doctrinales más importantes que en materia de salud laboral existían y logra, a su vez, resituar a los técnicos de prevención en el papel de agentes clave en el proceso transformador que nuestro modelo de relaciones laborales está, todavía hoy, llevando a cabo en lo que se refiere a la seguridad y salud laboral. Una obra, sin duda, llamada a convertirse en un estudio de referencia en la materia. 